\title{
The Effect of Jordanian Arabic upon the Production of English Language Among Academic College Professors across Jordan
}

تأثير اللغة الاولى (العربية /الأردنية) على استخدام اللغة الثانية ( اللغة الإنجليزية ) من قبل أساتذة الجامعات في الأردن

TamadurSulayman Al-Shamayleh tamadershamileh@yahoo.com

Phone number: 0772072724

المخلص

تمدف هذه الدراسة إلى معرفة مدى تأثير اللغة الأولى (العربية/ الأردنية) على استخدام اللغة

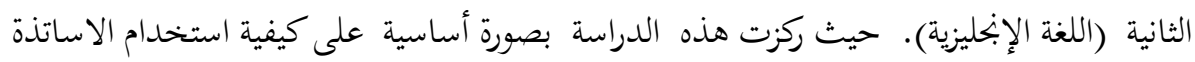

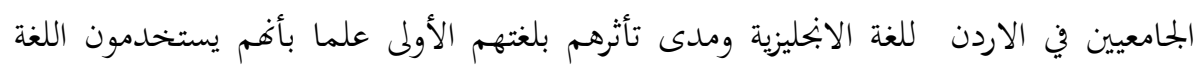

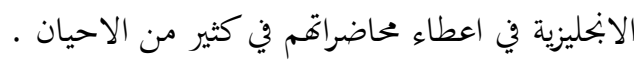

علاوة على ذلك، فإنها تمدف إلى تسليط الضوء على الدئ الدور الذي تلعبه بعض العوامل مثل

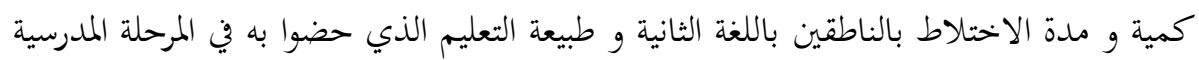

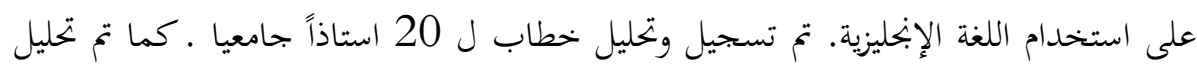
تأثيرات التداخلات الصوتية و اضافة أصوات و حذف أصوات ألخات أخرى و استبدال اصوات باصوات اخرى في أثناء النطق باللغة الابخليزية.

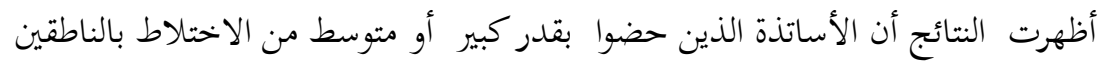

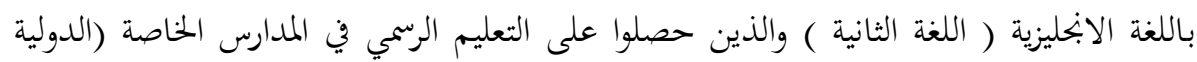

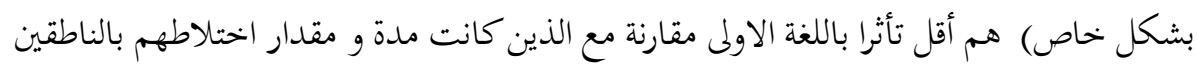
باللغة الانحليزية قليلة وحصلوا على التعليم الرميمي في المدارس الحكومية.

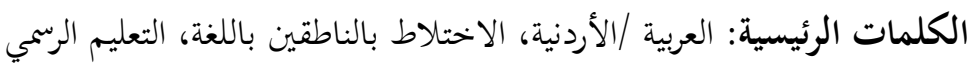

\section{Abstract:}

This study focuses on the effect of the first language (Jordanian Arabic) on L2 (English language) production. It 
aims to find out whether Jordanian professors whose first language is Arabic speak L2 (English) with a native-like accent or with the accent of their first language. Moreover, the role played by certain factors like the amount of exposure to L2 and their formal instruction on the production of L2 English is highlighted in this study. Towards this end, the speech of 20 professors was recorded and analyzed. Interference effects were also analyzed sound by sound. Thus, it was found out that professors who had a high amount of exposure to L2 English and who got their formal instruction in private (mainly international) schools display less L1 Jordanian Arabic than those with no/ little exposure to L2 and who got their formal instruction in public schools.

Keywords: Jordanian Arabic, language exposure, formal instruction

\section{Introduction:}

Jordanian Arabic has been influenced by the increasing contact with non-Arabic languages. These languages include Turkish, Kurdish, Circassian ...etc (Abu Ain, 2016). On the other hand, colonization and globalization play also a role in the spread of English in Jordan. All the types of contact have led to types of language shift, language mixing, borrowing, and code-switching. Moreover, such factors have led to phonological and lexical changes. It is already known that Jordan was under the occupation of Great Britain from 1961 to 1946. During and after this period, English was taught widely in Jordan. Its widespread is also traced to the effect of mass media since English is seen as the language of globalization and development; universal 
textbooks, periodicals, universal publications are all published in English. Moreover, many social and economic factors play a great role in the spread of English not only in Jordan, but in the whole world as well.

However, Jordanians cannot speak or use English well since there is no direct exposure to native speakers. Focusing on form and ignoring communication in the classrooms create a gap in learning English as a foreign language. Accordingly, the existence of two languages (Arabic and English) within the same community opens the border to language transfer (language interference). Arabic has its own distinguished syntactical, phonological, grammatical, and morphological features which are different from English! Such differences between two languages create negative transfer (learners commit errors as a result of the differences between two languages).

In this study, the participants belong approximately to the same social class since all of them are academic college professors. Academic College instructors use English in lectures, seminars, and conferences. However, the way they speak English could be a reflection of certain factors. This study examines whether Jordanian academic college instructors are influenced by their amount of exposure to L2 English as well as their formal instruction during their school level while speaking English or not.

\section{Review of related Literature:}

Hamdan and Abu Hatab (2009) states:

The reasons that motivated Jordanians to study English were (in rank order): to study or work abroad, to secure a decent job in Jordan, to be better informed about international 
events, and to develop a better understanding and appreciation of the values and traditions of people from various parts of the world" (p. 396).

Socially, English is often viewed as the most prestigious foreign language. As Al-Jarf (2005) states "people who study in English are more qualified and have a better social status than those who study in Arabic. Society respects those who can communicate in English and those who have graduated from an English medium college or university. Some pass and graduate with poor grades and a poor achievement level because of their poor English. A person who can communicate in English has better esteem and more self-confidence " (p.202).

Richards and Sampson (1972) discussed the factors that influence the learners' use of a foreign language. The most important factor was language transfer (language interference). According to the Behaviorist school (Lightbown and Spada, 2006); learners tend to transfer the forms, meanings, culture, and habits of their native language to the foreign language. As a result, the first language has a great effect on second language acquisition. All learning is socially mediated and that learners construct knowledge within the social relationship. Consequently, it is impossible to isolate learning from social relations. The role of L1 in the L2 depends on the degree of differences and similarities between the two languages. There are two assumptions of Contrastive Analysis in this regard: first, the degree of differences between L1 and L2 shows the degree of difficulty (what is known as negative transfer), second, the degree of similarities between L1 and L2 shows the degree of 
simplicity (what is known as positive transfer) (Hayati, 1998).

Learners of a second language rely on their first language whenever they want to write or speak in the target language (Derakhshan\&Karimi, 2015). As a result, if the structures of L1 and L2 are different, a lot of errors occur in L2. Errors that could be traced back to the first language while the learners use the second language are called " interference" (Bhela, 1999). According to Segalowits (1986), the first language could be distinct from the second language syntactically, phonetically, semantically, and rhetorically. If the syntactic structure of the second language is very different from that of the first language, a greater degree of cognitive restructuring is required. Language transfer indicates the use of first language knowledge and strategies to facilitate the learning of the target language. The transfer may occur consciously or unconsciously. According to Chomsky's (1979) Universal Grammar theory, humans produce language through a deep structure that enables them to generate and transfer their grammar to any other language. Consequently, learners naturally transfer their grammar to any other language; learners naturally transfer the skills they learned in the first language to the second language. O'Malley and Chamot (1990) define transfer as " the use of previous linguistic or prior skills to assist comprehension or production " (p.120).

Language transfer (mother tongue interference/ native language influence/mixing languages) is one of the major causes leading to learners; committing errors. When L2 learners lack proficiency in expressing themselves by 
using L2, they immediately rely on their L1 to express their ideas and thoughts. They use words and structures from their language to make them fit into the target language. Brown (2007) stated that transfer is the influence resulting from the similarities and differences between TL and any other language that has been previously acquired. Accordingly, transfer results from the interaction of previously acquired linguistic knowledge with the present learning. Thus, the two processes (language acquisition and language transfer) are linked since whenever a person starts to learn another language, the transfer process begins, The learners' knowledge of their L1 will be used in the L2 as a way to acquire the target language itself. This process occurs indirectly and unconsciously.

There are different kinds of errors that could occur in learning a second language. First, developmental errors have nothing to do with learners' first language. Second, ambiguous errors involve interference. Third, unique errors cannot be categorized either in interference or developmental errors (Dualy, Burt, and Krashen, 1982). Thus, it is suggested that if the learners have difficulty or errors in phonology, vocabulary, and grammar of L2, these are due to the interference of old habits from L1. It is important to mention that learners of a target language are not aware of their errors which result from language transfer and thus they are unable to correct these errors themselves. Contrastive analysis (a branch of comparative linguistics) is concerned with studying pairs of languages to predict where learners may / may not have difficulties and as a result making mistakes while learning the target language. 
The Merge hypothesis of Fleg (1987) points that the merging of phonetic properties of phones that are similar in the L1 and L2 can potentially impact not only the acquired language but the native one as well. He explains this point by stating the fact that many English speakers, with higher proficiency in Spanish, pronounce Spanish with English characteristics. This indicates that they can preserve their L1, but they cannot achieve native-like L2 pronunciation as a result of negative transfer. Others may lose their L1 and achieve native-like L2 pronunciation. Still, others may lose native-like pronunciation in both L1 and L2.

Kharma and Hajjaj (1989) and Zughoul (2003) are interested in studying the reasons for the weakness in English in Jordan although students study English for more than 12 years. They believe that the first step in addressing the weakness of school graduates in learning English is to identify and analyze the learners' errors while writing English which may be caused by the interference between L1 (Arabic) and L2 (English).

Also, many studies highlight the strong relationship between the learners' socioeconomic status and their academic achievement. Arikan (2011) states that people with high economic status (good salaries and income) can afford high educational expenses for themselves and their kids. Moreover, Arikan (2011) has discussed that even social class, housing, and access to resources have a considerable impact on the acquisition process as well as on academic achievement. Rich people are so concerned with their children's education, so they send their children to excellent private schools which afford a convenient learning 
environment, good textbooks and good teachers. Whereas the main interest of people with low-income is simply to strive to get money. Consequently, they are mostly less worried about their children's education.

Schumann $(1978,1986)$ in his acculturation hypothesis attempts to theorize the influence of social factors on L2 learning outcomes. He suggests that the degree to which the learner acculturates to the target language, the degree to which the learner acquires the target language. Thus, differential language learning outcomes are linked to psychological and social distance between second language learners and the target language group. Moreover, the learning process is seen as a re-evaluation of one's self-image and self-identification.

Norton (1997) states that there is an essential relationship between identity, language learning, and classroom teaching. Norton (2006, p.22) has referred to identity in SLA as " a socio-cultural construct in second language research." Pierce (1995) distinguished between " social identity " as referring to the relationship between individual and society and " cultural identity " as referring to an ethnic group association.

In many cases, speakers keep alternating (switching) between two languages or two dialects. This phenomenon is known as code-switching. Code-switching can be a possible language transfer because both (language transfer and codeswitching) reflect the influence of one language on another. It is already known that language is used to state ourselves. This indicates that language influences our self-concept and identity. Many speakers keep switching between L1 and L2 
to express gratitude or solidarity. They may alter the language to express group identification. According to Sert (2005), code-switching can be used for self-expression and to show personal intentions. Moreover, it could be used to create intimacy among members of a bilingual community. Fasold (1997) and Myers-Scotton (1998) argue that speakers might use code-switching to merge and belong to a specific group. The speaker may not be seen as a member of a certain social group. As a result, language transfer and code-switching comprise what is known as a cross-linguistic influence. Code-switching could take place whenever speakers cannot express themselves in one language so they alter to another language (usually the native language). Moreover, speakers could switch whenever they are distracted, tired, or less fluent in one language.

Migdadi (1997) investigated errors made by 100 first-year students (50 females and 50 males) and 100 secondyear students (50 females and 50 males) from the English language department at Yarmouk University in Jordan of the academic year 1996-1997. The study focused on the learners' use of the English relative clauses. Two tests were developed: a written translation test and a grammatical judgment test. The result of the study showed that students face difficulties in their use of the English relative clauses which could be traced to negative transfer from Arabic.

Bhela (1999) investigated cross-linguistic influence by studying the writing of four learners. Two sets of sequential pictures were given to them and they were asked to write a short beginning with the first picture and ending with the last picture. They were asked to write the same story 
firstly in the second language (English) then in their native language. Their errors were analyzed in both their L1 and L2 texts. The result of the study showed that learners made errors in L2 as a result of lacking of understanding of L2 and because of using the form of L1 while writing in $\mathrm{L} 2$. Consequently, errors are made in L2. The study also proved that with the existence of similarities in L1 and L2, the learners use the L2 easily. Also, they could use their structures to help them with their L2 texts.

Nawafleh (2008) conducted a study to illuminate the way people in Jordan communicate and the phenomenon of code-switching between English and Arabic. He believed that the process of communication is identity-defining patterns which include the speakers' cultural, ethnic, social, economic, and religious background. The result of the study revealed that code-switching could lead to some serious mutations in the Arabic language as well as may cause Arabic to lose its aesthetics as it has powerful meanings and expressive capacities.

Fatemi, Sobhani, and Abolhassani (2012) conducted a study to investigate the cause of Persian language learners' problems in the pronunciation of L2 (English). The sample of the study consisted of 30 females and males who were chosen randomly from three classes at Qeshm and Mashhad Language Institutes. Their age ranged between 18-30 years old. They were tested individually by reading six sentences. Each sentence included at least two clusters and the total number of these clusters was fourteen. The participants' oral production was recorded and analyzed. The result of this study revealed that the main cause of the problem in 
pronunciation is the difference between the syllable structure of Persian and English. Because of little or no similarities between the syllable structures of Persian and English, the learners try to use their phonological knowledge of syllabic structure that is already internalized.

Damra and Al-Qudah (2012) investigated the effect of using the native language (Arabic) on teaching English grammar. The sample of the study consisted of Ninth grade EFL students enrolled at Eskan Al Jubaiha secondary school in the second directorate of Amman in Jordan in the academic year 2010-2011. The sample of the study consisted of 80 female students who are distinguished randomly into an experimental group and a control group. The code-switching model was used to demonstrate that the best way of teaching English grammar could be either by using English without any reference to the native language or by using English supported by the native language. The study also focused on the students' attitudes towards using the native language in learning English grammar. The study was based on a grammar achievement test by which students were pre-tested to see if there are any differences in their achievement in grammar with taking into account that all items of the pretest were chosen from the covered material (Action Pack 9 / second-semester textbook). Students were post-tested on the three units after experimenting. Moreover, an attitude questionnaire was prepared to measure the attitudes of the students towards using the English language supported with Arabic if necessary or using English by itself. The findings of the study showed the importance of L1 use in teaching English grammar in the classroom. This encourages the use 
of the native language when there is no way students can understand or recognize English. Using the native language could help students to increase their awareness and knowledge about the similarities and differences between the two languages.

Tawallbeh (2013) investigated the influence of Colloquial Jordanian Arabic upon the use of negation and the definite article in English. The sample of the study consisted of 100 female and 100 male Jordanian tenth graders in the academic year 2011-2013 from public school in the region of Karak- Jordan. A translation test and a gap test were reconstructed. The finding of the study showed that students committed more transfer errors in their use of English negation and the definite article than other types of errors which is the result of the effect of Colloquial Jordanian Arabic.

Muftah and Galea (2013) also conducted a study to analyze errors on simple present tense among adult Arabs who were learning English. The study focused on the error on the third person singular present tense agreement morpheme $(-s)$. The sample of the study consisted of undergraduate adult Arabic speakers learning English as a foreign language. The data was gathered by designing a grammatical judgment task comprising both grammatical and ungrammatical items and elicited a written production task. Both tests were designed to test the learners' underlying knowledge of present simple tense. The grammatical judgment task consists of 12 grammatically (correctly) inflected items, 6 omission items, and 6 ungrammatically (incorrectly) inflected items. The most frequent errors types produced by adult Arab learners 
are omissions, phonological similarities, incorrect suffixation, and substitution. The finding of the study also revealed that adult Arab English learners have difficulty in mastering the use of the third person singular is due to first language interference.

Al-Mekhlafi (2013) also investigated the question formation errors made by 46 first-year university students whose major is English Language and Literature in the academic year 2009-2010 in Sohon University in the Sultanate of Oman. The study aims to reveal the kinds of errors that students make while forming questions in English. The participants were asked to write ten questions about " Wedding in the Sultanate of Oman". After analyzing the students' questions, it was obvious that students face difficulties regarding auxiliary omission, auxiliary replacement, auxiliary subject agreement, verbal from concord, auxiliary subject inversion, auxiliary redundant, wrong question word, and verb inversion. Such difficulties and errors were linked to the differences in the structures of question formation in L1 and L2.

Montero, Chaves, and Alvarado (2014) conducted a study to highlight the effect of factors such as motivation, cultural background, and economic status on the language acquisition process. The sample of the study included 56 students (males and females) who enrolled in the English Teaching Major from the Pacific Campus of the University of Costa Rica. The students came from different places in Costa Rica. The study is based on a case study supported by the quantitative paradigm. The result of the study showed the great influence of different social conditions on the effective 
learning of a second language. The learners' social background and their educational history as well as their motivation affect the degree of interference and the acquisition of L2. This means that individuals' different social and cultural experiences affect their educational outcomes as well as the degree of eagerness to learn L2.

Al-Zoubi and Abu-Eid (2014) conducted a study to examine the influence of the first language (Arabic) on learning English as a second language in Jordanian schools and its relation to educational policy. The sample of the study consisted of 266 high school graduates Jordanian students in the academic year 2013-2014. The students were given a translation test which consists of 24 items. The result of the research showed that the percentage of total error $(52.48 \%)$ committed by the study sample exceeds the percentage of correct answers $(47.52 \%)$. Students committed a lot of transfer errors which result from the effect of L1 since the majority of errors have to do with the use of the verb to be and the passive voice.

Ader and Miljan (2015) investigated the effect of external factors of second language learning on L2 sound production. The study aimed to compare the impact of a different cultural situation (exposure to the target language) on the informants' pronunciation. The sample of the study consisted of 97 speakers of L1 Estonian. They were divided into two groups: a younger generation and an older generation to focus on the quality and quantity of experience of L2 English and its interplay with age. The effect of setting on English learning (i.e the amount of time spent in the country where the target language is spoken or having an L1 
English teacher) and intensity of communication with native or non-native speakers of English have been taken into consideration. The comparison of the two groups clearly showed how exposure to native English influences pronunciation since the older generation started learning English at a later age and in a less exposure setting to the English language, unlike the younger generation. Consequently, the older generation influenced of L1 Estonian phonetic system, unlike the younger generation who influenced less of the L1 sound system on their L2 English.

\section{Methodology of the study:}

The sample of the study is designed to accurately deal with academic instructors who are originally purely Jordanian to examine the effect of Jordanian Arabic upon the production of the English language. The sample consists of 20 instructors. Variation in gender, age, specialization, formal instruction, and the amount of exposure to English has been taken into account. Studying this sample is deeply based on a structured (well-designed method which posed in the same way to all interviewees to get responses to the same phrasing) interview.

Many procedures are applied to get reliable data from the participants without any outside interference as well as to avoid observer's paradox (observing others' speech naturally without knowing that they are being observed ), Milroy's a friend - of $-\mathrm{a}$ friend procedure has also been applied.

The interviews are highly structured because all the participants (instructors) are triggered to do the same task. The instructors were given some carefully selected English 
sentences (long and short sentences) and phrases accompanied by some words. They are asked to read the given utterances. This task aims to check the pronunciation of certain sounds. The participants' observation technique is also used since it is a helpful tool in conducting qualitative sociolinguistic studies. The variables of the study include the amount of exposure to the second language and their formal instruction. The data is drawn from 20 Jordanian professors. Their speech is recorded and then analyzed together with a native speaker of British English. All the participants receive an individual number to maintain their anonymity. The informants are divided into two groups depending on their amount of exposure to L2 (English) and their formal instruction as the table (1) shows:

\begin{tabular}{|l|l|l|}
\hline Factor & Group (1) & Group (2) \\
\hline \hline $\begin{array}{l}\text { Amount of exposure } \\
\text { to L2 (English) }\end{array}$ & High / Middle & Low/ Never \\
\hline Formal instruction & Private & Public \\
\hline
\end{tabular}

The first group consists of 10 participants; two participants have a high amount of exposure to L2 in its natural settings and eight participants have a middle amount of exposure to L2. On the other hand, six participants of this group got their formal instruction in private schools. However, the second group consists of 10 participants; all of them have low/ never amount of exposure to L2 and they got their formal instruction in public schools.

After recording their speech, certain target phonemes are counted to check their sequences. The target phonemes under study are / t , p, 3 /, and consonants sequences. When a target phoneme was produced as in local Jordanian dialects up to two times, it was considered as inconsistent L1 
interference. When at least three times, it was regarded a consistent occurrence. When the sound is pronounced as the native speaker of English, the target sound was considered to be native-like.

\section{Results and findings:}

This study provides empirical data on the characteristics of sounds produced by L1 Jordanian Arabic speakers while speaking English.The relative frequencies of producing L2 English sounds as L1 Jordanian Arabic sounds are summarized in table (2).

\begin{tabular}{|c|c|c|}
\hline $\begin{array}{c}\text { English } \\
\text { sound/ feature }\end{array}$ & Group (1) & Group (2) \\
\hline \hline$/ \mathrm{g} /$ & $42.8 \%$ & $92,3 \%$ \\
\hline$/ \mathrm{p} /$ & $71,4 \%$ & $100 \%$ \\
\hline$/ \mathrm{z} /$ & $57.1 \%$ & $84.6 \%$ \\
\hline Consonant cluster & $42,8 \%$ & $100 \%$ \\
\hline
\end{tabular}

The data in this table reveals that in the production of specific L2 English sounds, many informants tend to use their L2 sound quality. The following table (table 3) demonstrates that.

\begin{tabular}{|l|l|l|l||}
\hline Group & Consistent & Inconsistent & $\begin{array}{l}\text { Native } \\
\text { like }\end{array}$ \\
\hline \hline 1 & $7,8 \%$ & $2,1 \%$ & $90,1 \%$ \\
\hline 2 & $89,7 \%$ & $5,3 \%$ & $5 \%$ \\
\hline
\end{tabular}

The results of the study (Table 2 ) revealed that $42,8 \%$ of the first group and $92,3 \%$ of the second group pronounce / $\mathfrak{f}$ / as / /maybe because / $\mathrm{g} /$ is not widely used in Jordanian Arabic. It is used in colloquial Jordanian Arabic, but it is highly stigmatized unlike / $\int /$ which is widely used in 
Standard and colloquial Jordanian Arabic. Although both sounds / $\mathfrak{t} /$ and / $/$ / have common phonetic features, the pronunciation of $/ \int /$ is simpler than $/ \mathrm{t} /$. As the results revealed, language transfer is higher among the participants of the second group unlike the participants of the first group. This demonstrates that exposure is an essential condition for acquiring L2 because it gives a learner a valuable chance of natural interaction. It could take the shape of doing certain activities such as interacting with other native speakers of $\mathrm{L} 2$, listening to the radio, watching TV, or reading books. Any learner needs to try to communicate in real situations to be fluent in L2.

It was found that very few people with fewer than three years of informal ESL exposure could use the language intelligibly for communication purposes or beyond the sentence level. Politzer (1965) observed that all immigrants coming to the US eventually learn to speak English because they keep exposing themselves to the target language environment. It is a vital way to practice the target language. This result goes in line with Rajagopal's survey. Rajagopal (1976) surveyed Malay-medium pupils in selected schools in Selangor. He observed that some pupils are less competent than others as a result of being handicapped by their environment. Those pupils got less opportunity and encouragement to practice speaking English at home or even at schools. Seliger (1977) classified learners depending on their desire to be exposed to the target language into two categories: learners who interact intensively and seek out opportunities to use L2, and those who either avoided 
interacting or have passive roles in language interaction situations.

English is a subject taught at schools in Jordan. Generally speaking, English is not used as a medium of instruction in public (government) schools, unlike most private schools in which English is used as a medium of instruction. Consequently, formal instruction does not permit much practice in the target language. English lessons are presented in small doses for about six hours a week in the government schools. Conversely, in most private schools English lessons are presented at least for about nine hours a week. All government schools follow the same curriculum and are staffed by teachers of similar qualifications. All teachers are Arabic native speakers. Learners are exposed to selected phonological, lexical, and thematic items. Learners lack the opportunity to speak, write and listen to native speakers. It is already known that one cannot understand a language without listening to it a great deal as well as one cannot learn to write a language without speaking it. The only sources of practicing speaking English are teachers and peers. Even teachers are not motivated enough to trigger students to learn English. Generally, they are far away from conducting classroom activities that would enhance L2 learning. Even vocabulary acquisition in an $\mathrm{L} 2$ has been associated with rote learning and memorization of words. Many English teachers use a mixture of English and Arabic languages during the English lessons. Their main concerns are to teach descriptive rules of grammar and memorizing words and their meanings.

In contrast, many private schools, mainly international schools, focus on the quality of instruction. Students are 
strongly motivated towards English, so they have favorable attitudes to learn it accurately. Learners have the opportunity for hearing, reading, and experiencing a wider contact with English so they become more competent in English. Teachers are triggered to use a variety of classroom techniques and to do heavy activities such as reading simple stories and books aloud, spending time talking about pictures and objects, and speaking only English during the lesson meeting time. Even the curriculum is developed accurately to increase the learners' competence effectively such as children creatively play and form words as they learn English and creating the meaning of these words.

Another examined feature is the pronunciation of the aspirated stop bilabial sounds /p/. As it is known, Arabic is characterized by the existence of unaspirated bilabial stop sound $/ \mathrm{b} /$ not $/ \mathrm{p} /$. Thus, all the participants of the second group pronounce $/ \mathrm{p} /$ as $/ \mathrm{b} /$. This problem has also its influence upon their writing; the participants were asked to fill certain blanks correctly either with $/ \mathrm{p} /$ or $/ \mathrm{b} /$ to get the correct spelling for certain words. Unfortunately, most of them did not know the correct spelling. Only a few proportions of the participants distinguish which words contain /p/ and which words contain /b/. The participants of the first group do well in this regard may be a result of the high amount of exposure to English in its natural setting which plays a role in distinguishing the differences between these two phonemes. Moreover, teaching English appropriately at schools and universities is a crucial point. As Habibah (1979, p.3) stated "With its status as a second language, being taught as one of the subjects in the school 
curriculum, English language teaching has been stripped of all the back-up it once had. This means a drastic reduction in contact hours, exposure to the language, and actual use of the language. "“

Another distinguishing phonetic feature that has been examined in this study is the pronunciation of $/ 3 / . / 3 /$ is not a standard sound in Jordanian Arabic; however, /ds / is the equivalent standard sound. It is widely used in standard and colloquial Jordanian Arabic. In this study, it was highly noticed that most participants (mainly among the second group) replaced / 3 / with / d / while pronouncing words such as; rouge, pleasure, treasure, measure...etc. The surprising result is that $84.6 \%$ of the second group replaced / 3 / with / $\mathrm{d} /$ whereas only $57,1 \%$ of the first group does that! After finishing the recording process, the participants heard the correct pronunciation of the selected sentences, phrases, and words. They were really surprised with the correct pronunciation, and they expressed their positive desire to train hard to pronounce words correctly. It is important to mention that $/ 3 /$ is used by some minorities in Jordan (especially among Syrian and some Palestinian refugees). Some look at this variant [3 ] as a marker of urbanization. Still, other pure Jordanians (mainly males) avoid using this variant because it is far away from their social identity as Jordanians.

Another noticeable feature that highlights the amount of interference between Jordanian Arabic and English is vowel insertion to avoid consonants' cluster (sequence). One of the salient features of Jordanian Arabic is to avoid consonants' sequences unlike English which contains patterns of 
consonants' sequences. This creates a kind of mispronunciation of English. In this study, $100 \%$ of the second group inserts vowels to avoid consonants' sequence. However, only $42,8 \%$ of the first group inserts vowels. The following table (table 4) shows the pronunciation of certain selected words among both groups.

\begin{tabular}{|l|l|l||}
\hline Word & Group (1) & Group (2) \\
\hline \hline School / sku:l/ & / sku:1/ & /Isku:1/ \\
\hline Fixed / fikst/ & / fikst/ & /ftkisd/ \\
\hline Asked / æskt/ & / æskt/ & / æskit/ \\
\hline Splash / splæ// & /splæ// & /Isplæ// \\
\hline
\end{tabular}

In rural and Bedouin Jordanian Arabic, the separation of any sequence of two consonants or more (mainly in final position) by a vowel is common. The influence of this feature causes a kind of misunderstanding in English. There is a considerable difference in this regard between the two groups. This goes with Shresta's study. Shresta (1998) also conducted a research to describe how both instruction and exposure attributed to the development of oral proficiency in English as a second language in mutually exclusive learning situations in Nepal. The sample of the study consisted of 58 randomly selected subjects who came from two distinct groups. The first group was composed of people who had learned English mainly through formal classroom instruction with grammar based approaches. The second group was composed of people who had learned English mainly through informal contact with English speaking people. Data were collected through personal interviews and presentations based on visual materials. The findings of the study revealed that both instruction and exposure contributed to second 
language acquisition in their own unique ways, instructions seemed to promote accuracy but exposure seemed to promote fluency. It is already known that in communicating an oral message, fluency is more important than accuracy. Therefore, teaching new languages shall not be like teaching other subjects at schools or even universities.

\section{Conclusion:}

The main interest of this study is to investigate the influence of the L1 (Jordanian Arabic) on L2(English)production among Jordanian College professors and its relation to the amount of exposure to L2 (English) and the participants' preceding formal instruction during their school level.

The study has revealed that Jordanian College professors who have little/ no exposure to L2 (English) in its natural setting and who got their formal instruction in public schools suffer from a high degree of negative language transfer. Unlike those who have high/ middle exposure to L2 (English) in its natural settings and got their formal instruction in private schools, they have less effect of negative language transfer.

Thus, exposure to L2 in its natural setting is so important to be far away from negative language interference. Moreover, schools shall follow an effective educational policy by focusing on communication more than teaching any second language to increase students' L2fluency and proficiency. 


\section{References:}

Abu Ain, N. (2016). A Sociolinguistic Study in Saḥam, Northern Jordan. PhD Diss., University of Essex.

Ader, K. \&Miljan, M. (2015). External factors and the interference of L1 Estonian on L2 English pronunciation: An apparent -Time Study. Eesti Rakendus linguistic aühingoa astaraamat, 11, 21-36.

Al -Zoubi, D.M. \& Abu-Eid, M.A. (2014). The influence of the first language (Arabic) on learning English as a second language in Jordanian schools, and its relation to Educational Policy: Structural errors. Sino-US English Teaching, 11 (5), 355-372.

Al-Jarf, R. (2005). The impact of English as an international language (EIL) upon Arabic in Saudi Arabia. Asian EFL Journal, 10 (4), 193-210.

Al-Mekhlafi, M. A. (2013). A study of question formation in the English writing of Omani EFL learners. Standard Journal of Education and Essay, 1 (4), 57-62.

Arikan, A. (2011). Prospective English language teacher's perceptions of the target language and culture in relation to their socioeconomic status. Canadian center of science and education, 4 (3), 232-242 Retrieved on September 2012, from www.ccsenet.org/elt.

Bhela, B. (1999). Native language interference in learning a second language: Exploratory case studies of native language interference with target language usage. International Education Journal, 1 (1), 22-31.

Brown, H. D. (2007). Principles of language learning and teaching $\left(5^{\text {th }} \mathrm{ed}\right)$. New Jersey: Pearson Education Limited. 
Chomsky, N. (1979). Language and responsibility. New York: St. Martin's Press.

Darma, H.M. \& Al Qudeh, M. (2012). The effect of using native language on grammar achievement and attitudes toward learning of basic stages EFL students in Jordan. International Journal of Business and Social Science, 3 (1), 300-306.

Derakhshan, A. \& Karimi, E. (2015). The interference of first language and second acquisition. Theory and practice in language studies. 5 (10), 2112-2117.

Dulay, H., Burt, M. \&Krashen, S (1982). Language two. New York: Oxford University Press.

Fasold, R. (1997). The sociolinguistics of society. Oxford: Blackwell Publishers.

Fatemi, M.A., Sobhani, A. \&Abolhasani, H. (2012). Difficulties of Persian learners of English in pronouncing some English consonant clusters. World Journal English Language, 2 (4), 69-75.

Fleg, J.E.(1987). The production of "new" and "similar" phones in a foreign language:evidence for the effect of equivalence classification. Journal of phonetic, 14, 47-65.

Habibah,S. (1979). ' The ITM's English program for the eighties.' Paper presented at the national seminar on the Teaching of English in Institutions of Higher Learning in the 1980's, Institute Tecknologi MARA, Shah Alam, 1979.

Hamdan, J.M. \& Abu Hatab, W. A. (2009). English in the Jordanian context. World English, 28 (3), 394-405.

Hayat, M. (1998). A Contrastive analysis of English and Persian stress. Papers and studies in contrastive linguistic, 34, 53-72. 
Kharma, N. \&Hajjaj, A. (1989). Use of the mother tongue in ESL classroom. IRAL, 27 (3), 223-235.

Lightbown, P.M. \&Spada, N. (2006). How languages are learned. Oxford: Oxford University Press.

Migdadi, A.H. (1997). The role of native language in foreign language learning: An investigation of university students' errors in English relative clauses (MA thesis), Yarmouk University, Jordan.

Montero, R.L, Chaves, M.J. \& Alvarado, J.S. (2014). Social factors involved in second language learning: A case study from the Pacific Campus, Universidad de Costa Rica. Revista De LenguasModernas, 20, 435-451.

Muftah, M. \&Galea, S.R. (2013). Error analysis of present simple tense in the inter language of adult Arab English language learners. English Language Teaching, 6 (2), 146-154.

Myers-Scotton, C. (1998). Codes and sequences: Choosing linguistic varieties. New York: Oxford University Press.

Nawafleh, A. M. (2008). CS in the Jordanian society (Unpublished thesis), Al-Hussein Bin Talal University, Amman: Jordan. (online ), available:

Norton , B. (1997). Language, identity, and the ownership of English. TESOL Quarterly ,31 (3), 409-429.

O'Malley, J.M. \&Chamot, A.U. (1990). Learning strategies in second language acquisition. New York: Cambridge University Press.

Peirce, B.N. (1995). Social identity, investment, and language learning. TESOL Quarterly, 29(1), P. 9-31. 
Politzer , R. (1965). Foreign language learning: a linguistic introduction. Englewood Cliffs, New Jersey: Prentice Hall, Inc.

Rajagopal, S. (1976). A study of the role of attitudes and motivation in the acquisition of English as a second language by $5^{\text {th }}$ form Malay-medium pupils in Selangor. Unpublished MED dissertation, University of Malaya.

Richard, J.\& Sampson, G. (1972). The study of learner English. In J.C. Richards (Ed.), Error Analysis: Perspectives on second language acquisition (3-18). London: Longman Group Limited.

Schumann, J. (1978). The acculturation model for second language acquisition. In R.Gingras(Ed.). Second language acquisition and foreign language teaching, 27-50. Washington, DC: Center for applied linguistics.

Schumann, J. (1986). Research on the acculturation model for second language acquisition. Journal of multilingual and multicultural development, 7 (5), 379-392.

Segalowitz, N. (1986). Skilled reading in the second language. In J. Vaid (Ed.), language processing in bilinguals: Psycholinguistic and Neuropsychological perspectives. Hillsdale, NJ: Lawrence Erlbaum.

Seliger, H. (1977). Does practice make perfect? A study of interaction patterns and L2 competence. Language Learning, 27, p.263-278.

Sert, O. (2005). The functions of CS in ELT classrooms. The Internet TESL Journal, 6 (8), online, available: http://iteslj.org/Articles/Sert-codes witching.html. 
Shresta, T.B. (1998). Instruction and exposure: How do they contribute to second language acquisition? Foreign Language Annals, 31 (2), p.232-242.

Tawalbeh, I. (2013). The effect of Colloquial Jordanian Arabic on learning the English definite article and negation. English Language Teaching, 6 (8), 95-107.

Tawalbeh, I. (2013). The effect of Colloquial Jordanian Arabic on learning the English definite article and negation. English Language Teaching, 6 (8), 95-107.

Zughoul, M. (2003). Globalization and EFL/ESL pedagogy in the Arab World. Journal of language and learning, 1 (2), 106-146. Retrieved from: http://webspace.buckingham.ac.uk/kbernhardt/journal/jellea $\underline{\text { rn/1-2/zughoul. html }}$ 